\title{
Management challenges at end-of-life in a patient with agitated delirium and benzodiazepine withdrawal at comprehensive cancer care center
}

\author{
Sola Kim", Ali Haider", Akhila Reddy, Eduardo Bruera \\ Department of Palliative Care, Rehabilitation, and Integrative Medicine, The University of Texas MD Anderson Cancer Center, Houston, TX, USA \\ \#These authors contributed equally to this work. \\ Correspondence to: Ali Haider, MD, Assistant Professor. Department of Palliative Care, Rehabilitation and Integrative Medicine, Unit 1414, The \\ University of Texas MD Anderson Cancer Center, 1515 Holcombe Blvd, Houston, TX 77030, USA. Email: ahaider@mdanderson.org.
}

\begin{abstract}
Most people have some idea of how they want to live their life; however, an estimated twothirds of Americans have not completed their advance directives. This becomes an issue when up to $90 \%$ of patients develop delirium during their final days of life, at which point we depend on advance directives or surrogate decision-makers. Here, we present a case of terminal delirium in a patient with advanced cancer and a history of alprazolam abuse who had not discussed his end-of-life wishes with the medical team or with his estranged family. Treatment was provided to address reversible causes of delirium, including correcting electrolyte imbalances, urinary retention, and administered antibiotics for purulent otitis media. Hyperactive delirium was managed aggressively with intravenous neuroleptics and benzodiazepine, while keeping a balance between somnolence and control of agitative symptoms. Without knowing the patient's wishes, the family continued to struggle with decision making. However, with multidisciplinary team approach patients and caregivers' symptoms were better managed. Family then requested us to transfer him to a local hospice facility. The patient eventually passed away peacefully surrounded by his family members. This case highlights the importance of advance care planning, addressing emotional distress in estranged family members regarding symptom burden, and developing the appropriate treatment regimen for a delirious patient with a history of benzodiazepine abuse. Our case serves as a reminder of the support, guidance, and impact that inpatient palliative care teams can offer to both the patient and caregivers.
\end{abstract}

Keywords: Case report; delirium; end-of-life care; advance directives; palliative care

Submitted Feb 27, 2020. Accepted for publication Sep 18, 2020.

doi: $10.21037 /$ apm-20-495

View this article at: http://dx.doi.org/10.21037/apm-20-495

\section{Introduction}

In the United States, autonomy is seen as one of the four ethical principles that govern making critical medical decisions (1). Although most people have some idea of how they want to live their life, an estimated two-thirds of Americans have not completed advance directives (2). This becomes an issue when up to $90 \%$ of patients develop delirium during their final days of life, described as an acute fluctuating disturbance in attention, awareness, and cognition, including disorganized thinking, memory impairment, disorientation, or perceptual disturbance (3).
Should this manifest, we depend on advance directives or surrogate decision-makers. Unfortunately, those who lack advance directives may receive aggressive measures that are not in line with their goals of care and may exacerbate suffering. This situation can become more challenging to manage when a patient's estranged family re-emerges at the end of the patient's life. Here, we present a case of managing terminal delirium in a patient with advanced cancer and a history of alprazolam abuse who had not discussed his end-of-life wishes with the medical team or with his family. Efforts to navigate interactions with 
the family and with the healthcare team are presented as well. We present the following article in accordance with the CARE guideline checklist (available at http://dx.doi. org/10.21037/apm-20-495).

\section{Case presentation}

All procedures performed in studies involving human participants were in accordance with the ethical standards of the institutional research committee and with the Helsinki Declaration (as revised in 2013). Written informed consent was obtained from the patient.

Mr. C is a male, in his forties with a history of recurrent, metastatic head and neck cancer who had been lost to follow-up. He presented with intermittent confusion and frequent falls. The patient was accompanied by his brother, who stated that Mr. C lives with their mother, who has the major neurocognitive disorder; Mr. C is estranged from other family and friends. Mr. C's brother periodically checked on their mother's well-being, and subsequently, on Mr. C's. During his most recent visit, Mr. C's brother discovered that Mr. C had fallen and was confused. The patient's brother decided to bring Mr. C to the hospital, where he hoped Mr. C. would receive cancer-directed therapy.

Unfortunately, imaging showed the progression of the patient's disease. Magnetic resonance imaging (MRI) of the cervical/thoracic/lumbar spine showed extensive disease involving multifocal osseous lesions to the spine at C4, C7, and T1. MRI of the brain showed a stable mass effect on left frontal and temporal lobes. On admission, the patient was alert; was oriented to person, place, and time; answered questions appropriately, and was able to ambulate independently. He had a history of known right upper extremity weakness due to the left-sided tumor mass. However, within 24 hours of the patient's hospitalization, he developed progressively worsening delirium. Given the extent of Mr. C's cancer and confusion, the oncology team discussed his grim prognosis with his brother; $\mathrm{Mr}$. C was no longer a candidate for cancer-directed therapy.

Our palliative care team was consulted to assist with symptom management and with the transition of care. Agitated delirium was the main distressing symptom and started haloperidol at $2 \mathrm{mg}$ was initiated intravenously (IV) and administered every 2 hours as needed; however, even after receiving multiple doses, the patient's symptoms were not controlled. During a thorough discussion with the patient's brother, we discovered that the patient had a long history (years) of alprazolam abuse. Review of the Texas Prescription Monitoring Program confirmed multiple prescriptions from different providers in the two months immediately before admission. The amount of benzodiazepine that the patient took was not known since delirium limited further evaluation, but the family confirmed that empty bottles of alprazolam were seen throughout the patient's home.

Mr. C had three children, one of whom was an adult. The children had also been estranged from the patient and agreed to allow Mr. C's brother to be the surrogate decision-maker. Given the severity of symptoms and disease progression, we proceeded to discuss the goals of care with Mr. C's brother, who understood that treatment was no longer an option and wanted to keep the patient comfortable. He agreed to transfer the patient to our Palliative Care Unit for aggressive symptom management, with the goal of transitioning the patient to hospice care in the patient's community. We continued to address reversible causes, including correcting electrolyte imbalances, urinary retention, and administered antibiotics for purulent otitis media. Despite this treatment, there was no improvement in Mr. C's symptoms.

Mr. C's agitated delirium continued to worsen. Mr. C's brother appeared exhausted and was frustrated because he wanted to keep the patient as lucid as possible while attempting to control his delirium. Mr. C's brother repeatedly asked us to limit his brother's sedating medications, knowing that this caused the patient to "sleep all the time." Our psychosocial team continued to visit with Mr. C's brother and eldest daughter, who came to the hospital after Mr. C was transferred to the Palliative Care Unit. Both expressed feelings of guilt, having been estranged from the patient and missing their opportunity to help Mr. C with obtaining adequate treatment for his cancer. They were attempting to hold on to his episodes of consciousness to feel like they were present with him. We continued to explain to Mr. C's brother that we were attempting to maintain a balance between somnolence and control of delirium. The healthcare team became distressed as Mr. C's agitation continued to worsen, requiring a bedside sitter to keep Mr. C safe. At this point, the family agreed to aggressive symptom management.

We then prescribed haloperidol at $2 \mathrm{mg}$ IV and lorazepam at $1 \mathrm{mg}$ IV, both given every 6 hours. The reason for adding a benzodiazepine was to assist with benzodiazepine withdrawal, which might have been contributing to the patient's delirium. The addition of 
lorazepam appeared to improve control of the agitation; however, both the nursing staff and family at the bedside reported worsening agitation after haloperidol administration. We subsequently replaced haloperidol with chlorpromazine, starting at $25 \mathrm{mg}$ every 4 hours as needed, and monitored the patient's symptoms closely for several days. The patient's final regimen included chlorpromazine at $75 \mathrm{mg} \mathrm{IV}$ and lorazepam at $2 \mathrm{mg} \mathrm{IV}$, both given every 6 hours, which provided reasonable control of the patient's psychomotor agitation.

The family felt relieved as that patient's agitation was controlled, and he appeared to be resting comfortably. The family then requested that the patient be moved closer to their hometown so that other family members could pay their final respects. Mr. C was discharged and taken by ambulance to an accepting inpatient hospice facility. $\mathrm{He}$ died peacefully two weeks later, surrounded by his reunited family. Figure 1 shows the timeline of the patients' clinical course during the hospitalization.

\section{Discussion}

Having discussions with the health care team about the goals of care before Mr. C's delirium could have reduced the burden of decision-making of family members, endof-life hospitalizations, and moral distress while increasing the likelihood that the patient's wishes were respected and that he would receive care that was consistent with his preferences, values, and beliefs (4).

Some physicians may find it challenging to have end-of-life discussions due to several factors such as personal discomfort, lack of time, lack of training or resources, or lack of accessibility and utility of advance directives (5). Physicians may also believe that patients may be uncomfortable, frustrated, or more stressed when discussing end-of-life measures. However, $89 \%$ of Americans were in favor of addressing end-of-life issues with their healthcare provider (6). Despite this, fewer than one in five has an advance care planning conversation with their healthcare provider (7). This highlights the importance of providing information about this subject to health care providers and of explaining the benefits of advance care planning in terminally ill patients, especially those estranged from their family, as was the case with Mr. C.

The last six months of life for cancer patients are typically characterized by functional decline and poorly controlled symptoms, including pain and confusion (8). During this period, early palliative care, compared with standard care alone, can lead to significant improvements in both quality of life and mood as well as less aggressive care at the end of life (9). Thus, familiarity with necessary comfort measures is an essential skill for all clinicians whose patients face imminent death.

Delirium is one of the most common neuropsychiatric complications in patients with advanced cancer and can be the most distressing to the patient's family (10). Altered consciousness impedes communication with the family and limits the patient's ability to participate in treatment decisions actively (11). Furthermore, as seen with Mr. C's family, the signs and symptoms of delirium cause emotional distress. Preparing caregivers to deal with delirium would relieve suffering and allow the caregivers to support the patient more effectively.

Delirium remains underdiagnosed and may result in mismanagement of disease. As described in our case, several days passed before Mr. C's delirium was identified and appropriately treated. For this reason, a thorough medical history, close clinical observation, and a high level of suspicion are needed to facilitate early diagnosis (12). The mainstay of therapy involves identifying reversible causes and managing hyperactive features with neuroleptics, although the use of benzodiazepines to treat delirium has also been shown to be effective (13).

Our case is unique because it highlights the challenges experienced by non-compliant and socially isolated advanced cancer patients at the end-of-life. We have also demonstrated the importance of a dedicated inpatient palliative care unit in a comprehensive cancer center, where a multidisciplinary team approach can be utilized to care for such patients and their caregivers. Our case is also unique because it highlights the importance of early detection and effective management of delirium which can be more challenging in the case of benzodiazepine withdrawals. Our findings are limited due to a lack of scientific rigor and inability to generalize to a broader population or in a different clinical setting. Further investigation in determining the optimal drug combination in managing delirium is needed.

\section{Conclusions}

Multiple issues may arise in patients who develop delirium. This case highlights the importance of advance care planning, addressing emotional distress in estranged family members regarding symptom burden, and developing the appropriate treatment regimen for a delirious patient 


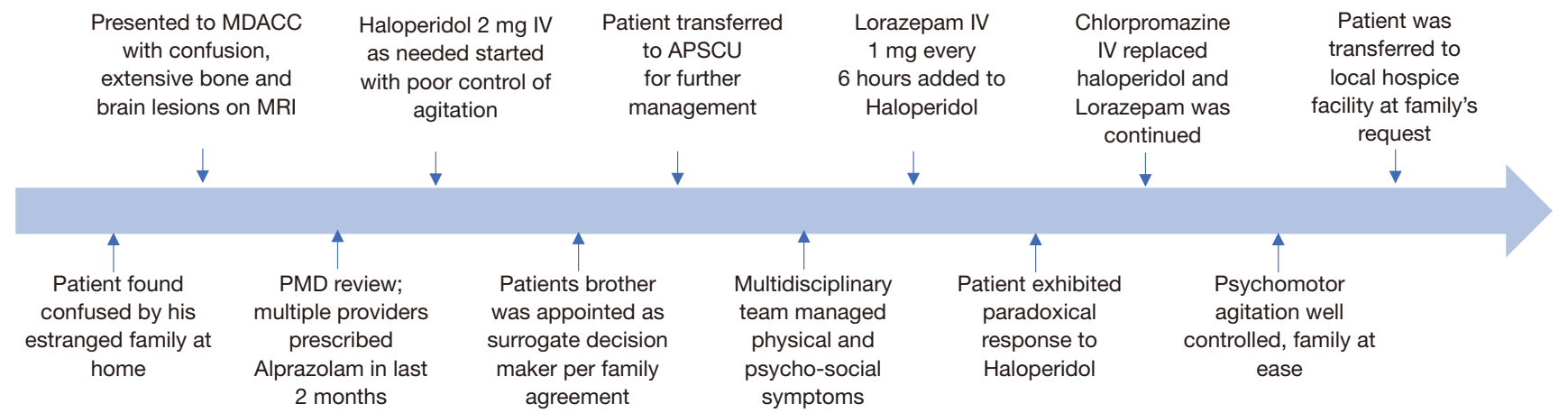

Figure 1 Timeline to show patients clinical course during hospitalization. MDACC, MD Anderson Cancer Center; PMD, Prescription Monitoring Database; IV, intravenous; APSCU, Acute Palliative and Supportive Care Unit.

with a history of benzodiazepine abuse. Our case serves as a reminder of the support, guidance, and impact that palliative care and hospice services offer to both the patient and caretakers.

\section{Acknowledgments}

This study was presented in part at the Multinational Association of Supportive Care in Cancer (MASCC) Annual Meeting, Vienna, Austria, June 28-30, 2018.

Funding: None.

\section{Footnote}

Reporting Checklist: The authors have completed the CARE reporting checklist. Available at http://dx.doi.org/10.21037/ apm-20-495

Peer Review File: Available at http://dx.doi.org/10.21037/ apm-20-495

Conflicts of Interest: All authors have completed the ICMJE uniform disclosure form (available at http://dx.doi. org/10.21037/apm-20-495). The authors have no conflicts of interest to declare.

Ethical Statements: The authors are accountable for all aspects of the work in ensuring that questions related to the accuracy or integrity of any part of the work are appropriately investigated and resolved. All procedures performed in studies involving human participants were in accordance with the ethical standards of the institutional research committee and with the Helsinki Declaration (as revised in 2013). Written informed consent was obtained from the patient's next of kin for publication of this case report. A copy of the written consent is available for review.

Open Access Statement: This is an Open Access article distributed in accordance with the Creative Commons Attribution-NonCommercial-NoDerivs 4.0 International License (CC BY-NC-ND 4.0), which permits the noncommercial replication and distribution of the article with the strict proviso that no changes or edits are made and the original work is properly cited (including links to both the formal publication through the relevant DOI and the license). See: https://creativecommons.org/licenses/by-nc-nd/4.0/.

\section{References}

1. Macklin R. Applying the four principles. Journal of medical ethics 2003;29:275-80.

2. Yadav KN, Gabler NB, Cooney E, et al. Approximately One In Three US Adults Completes Any Type Of Advance Directive For End-Of-Life Care. Health Aff (Millwood) 2017;36:1244-51.

3. Hosie A, Davidson PM, Agar M, et al. Delirium prevalence, incidence, and implications for screening in specialist palliative care inpatient settings: a systematic review. Palliat Med 2013;27:486-98.

4. Teno JM, Gruneir A, Schwartz Z, et al. Association between advance directives and quality of end-of-life care: a national study. J Am Geriatr Soc 2007;55:189-94.

5. Biondo PD, King S, Minhas B, et al. How to increase public participation in advance care planning: findings from a World Café to elicit community group perspectives. BMC Public Health 2019;19:679.

6. Mooney DC, O'Gorman JG. Construct Validity of the Revised Collett-Lester Fear of Death and Dying Scale. 
Omega 2001;43:157-73.

7. Poll KHT. The Henry J. Kaiser Family Foundation website. 2015. Accessed December 2019. Available online: http://kff.org/health-costs/poll/finding/Kaiser-healthtracking-poll

8. McCarthy EP, Phillips RS, Zhong Z, et al. Dying with cancer: patients' function, symptoms, and care preferences as death approaches. J Am Geriatr Soc 2000;48:S110-21.

9. Temel JS, Greer JA, Muzikansky A, et al. Early palliative care for patients with metastatic non-small-cell lung cancer. N Engl J Med 2010;363:733-42.

10. Bruera E, Bush SH, Willey J, et al. Impact of delirium and recall on the level of distress in patients with

Cite this article as: Kim S, Haider A, Reddy A, Bruera E. Management challenges at end-of-life in a patient with agitated delirium and benzodiazepine withdrawal at comprehensive cancer care center. Ann Palliat Med 2021;10(6):6979-6983. doi: 10.21037/apm-20-495 advanced cancer and their family caregivers. Cancer 2009;115:2004-12.

11. Fritz L, Dirven L, Reijneveld JC, et al. Advance Care Planning in Glioblastoma Patients. Cancers (Basel) 2016;8:102.

12. Bruera E DS. The MD Anderson Supportive and Palliative Care Handbook. University of Texas Printing \& Media Service, 2015.

13. Hui D, Frisbee-Hume S, Wilson A, et al. Effect of Lorazepam With Haloperidol vs Haloperidol Alone on Agitated Delirium in Patients With Advanced Cancer Receiving Palliative Care: A Randomized Clinical Trial. JAMA 2017;318:1047-56. 